\title{
AUTONOMOUS LEARNING STRATEGY OF THE SUCCESSFUL NONTRADITIONAL STUDENTS
}

\author{
Siti Zulaihah \& Ratri Harida \\ Zul_jayadi@yahoo.com
}

STKIP PGRI Ponorogo

\begin{abstract}
Most students of English Education Program in STKIP PGRI Ponorogo can be considered as nontraditional students with family, work, and other life responsibilities which have many influences on their educational goals. Autonomous learning is a customized way of learning applied by individual to find out his own learning needs and learning goals, decide the most appropriate way for his own learning, as well as to monitor and evaluate the learning progress. This research used qualitative descriptive method. The primary techniques in data collection were questionnaire, and interview. In general, the most influential motivation for the students was internal motivation. Advisor's availability, text book, internet, supportive atmosphere, self discipline, cozy and quiet place, and early morning were among the students' choices for their autonomous learning. They frequently used music, film, video, essay, and smart phone application in their study. In general, the nontraditional students with high achievement were often felt easy to understand the material especially when it was delivered in relatively "easy" language, expressed their opinion bravely, and patient in doing their tasks. They considered friends, best friends, and lecturer as people who were capable to help them in doing autonomous learning
\end{abstract}

Keywords: autonomous learning strategy, nontraditional students, successful

\section{A. INTRODUCTION}

Most of the students of English Education Program of STKIP PGRI Ponorogo choose to work in the morning and go to lecture in the afternoon to evening. They do it because the lecturings in STKIP PGRI Ponorogo are started on 14.30. The number of working students grows with regard to their year in college. Choy in Buvoltz, Powell, Solan \& Longbotham (2008) classified this type of students as nontraditional students. Nontraditional students usually have families, working responsibilities, and any other life's situation which can affect their success for educational goal. Generally, nontraditional students find a flexible and short-time program to fulfill their educational goals while balancing their family and job responsibility (Choy in Buvoltz, et.al., 2008). Autonomous learning skill helps the non-traditional students to fulfill their tasks and responsibilities especially for academic purpose. Chamot and Kupper's research (McDonough, 2001) revealed that successful students use their learning strategies more often, more efficient, and varied. In contrast, the less successful students have fewer and even less applicable learning strategies.

There were two main goals of the research, (1) to find out the autonomous leaning strategies that were applied by the students of English Education Department of STKIP PGRI Ponorogo, and (2) to find out the reasons of English Education Department of STKIP PGRI Ponorogo to apply the strategy. The results of the research were aimed to (1) enrich the literature on students' learning strategy in higher education level, (2) provide references for English Education Program's lectures for constructing materials that supports students' learning autonomy, and (3) accelerate the students' learning success because it can be used as a model of successful students' learning strategy.

\section{B. LITERATURE REVIEW}

\section{Definition of Autonomous Learning}

The findings of Buvoltz et.al.'s research (2008) assumed in the context of nontraditional students which is similar to the nontraditional students in STKIP PGRI Ponorogo, the ability to do autonomous learning is highly related to their emotional quotient. The control on feelings, wishes, optimism, confidence, adaptability, drive for achievement, communication, conflict management, and the ability to cooperate, which are associated with emotional quotient are essential elements of autonomous learning.

In conclusion, autonomous learning is a particular way of learning which is applied by an individual due to his ability to find out his own learning needs, set his own learning goals, set the most appropriate way for his own 
learning, and how to monitor and evaluate his own learning progress. Students who learn autonomously do not put aside the need of classroom learning, and the lecturing. They still need the classroom and lecturer that can support their autonomous learning and to learn in harmony within the classroom. In this type of learning, Zoghi \& Dehghan (2012) defined the students as their own "active learning manager" and the lectures only role as the facilitator which provide space for students' autonomous learning progress. Alongside the emotional quotients which mainly based on the self control, the lecturers' role is also very essential in the application of autonomous learning.

\section{Autonomous Learning Strategy}

According to O'Malley \& Chamot (Wang, 2010), autonomous learning strategy can be divided into three; cognitive strategy, metacognitive strategy, and social mediation strategy. Technically, the cognitive strategy is done through the method of reading, remembering, note-taking, and questioning. The metacognitive strategy involves the activity of planning the learning, data collection, self supervision, self evaluation, learning reflection, and arrangement of the individual's learning file. Social mediation includes the relaxed behavior during the learning activities, the making of group's rule, the cooperation with fellow students, effective communication, and help for evaluating fellow students' task (Wang, 2010).

Metacognitive strategy is the most dominant strategy to apply in various researches on autonomous learning strategy process. Guo (2012) stated that metacognitive strategy is effective to increase the language students' skills in listening course.

In the teaching of English, especially for reading skills, Sariçoban, (2012) divided this strategy into twelve strategies: "St1: reviewing and connecting the learned materials ", "St2: paying attention", "St3: directed attention", "St4: selected attention", "St5: organizing progress", "St6: determining purposes and aims", "St7: identifying the purpose of language tasks ", "St8: planning the aims of language tasks", "St9: finding any opportunities to practice", "St10: self management", "St11: self monitor", and "St12: self evaluation". Based on the result of the research, those metacognitive strategies are significantly related to the autonomous learning in reading course (Sariçoban, 2012).

Flexibility in determining the pattern of self learning is the characteristic of autonomous learning pattern. In Kupetz \& Ziegenmeyer's research (2006) flexibility supports the success of autonomous learning in learning English both in the classroom and online.

\section{Merits and Drawbacks of Autonomy Learning}

Autonomy learning has merits if it is compared to traditional class. According to some studies by Long, PaoNan, and Wei-Fan (in Francis and Flanigan, 2012: 2), autonomy learning shows a positive correlation with students' achievement. The advantages of autonomy learning are: (1) giving the same opportunities for different level of students; (2) encouraging students' confidence and responsibility; (3) focusing the students' attention. These strengths focus on individual learning.

There are some drawbacks of autonomy learning. The drawbacks are: (1) student-teacher interaction is less intensive since autonomy learning focuses on individual learner; (2) some teachers and learners are quite uncomfortable because both may employ different learning strategy; (3) it is pretty troublesome to handle strictly different learning achievements of each learner; (4) all learning components need an extra hard-working to achieve goals as what have been planned in the beginning.

\section{RESEARCH METHODOLOGY}

This research used qualitative research method to describe the autonomous learning strategy applied by the students, their reason of choosing the strategy, and the effect of the strategy application for fulfilling their learning goals. The primary techniques in data collection were questioner and interview. The questioner was divided into two parts. The first part consisted of questions and information of the subject (name, age, and level), questions about extracurricular and/or other productive activity besides learning in the college, marital status, and number of children. The second part was an adapted version of Tassinari, 2012. There were four statements in beginning of the second part. The statements were related to the students' motivational and emotional ability. The next part consisted of thirtytwo statements which were related to the students' ability in constructing knowledge. This questioner was more into O'Malley \& Chamot's metacognitive and social mediation strategy. The cognitive strategy was not explicitly stated in the questionnaire. 
There are twentyfour open-ended questions given to the subjects. The students chosen for this research must meet certain criteria. Considering that the students of academic year 2015 and 2016 had less academic records than the students of academic year 2013 and 2014, the researchers decided to choose the students with of academic year 2013 and 2014 as the subjects of the study. Another criterion was having more than 3.5 GPA. This criterion was set based on the assumption that students with more than 3.5 GPA is considered as students satisfying academic capability compared to the other students. It also indicates that the students have already applied effective autonomous learning strategy. Other criteria of the subjects were they must have documents which could prove their achievement in either academic or non academic, and they must have any other evidences of their productive activity. There were ten students who met all the previous criteria; six students of the academic year 2013 and four students of the academic year 2014.

This research also employed documentation technique to support the data collection. This research collected and analyzed any records or documents which are related to the students' autonomous learning process. The documents covered KHS (Students' Learning Result), certificate, or other documents that can prove their academic and non academic achievement. All of the data were then analyzed through the steps as follow; selection categorization, conclusion, and verification.

\section{RESULT AND DISCUSSION}

\section{General Description}

The general description was taken from the information in the first part of the quissionaire. Most of the subjects (80\%) were actively involved in Students Activity Unit and got important position such as the chief of Students Union, the secretary, and document coordinator of particular Students Activity Unit. 60\% of the students had other activities besides studying in the college such as working in formal educational institution and becoming entrepreneurs. Only one out of ten subjects (10\%) had married and got a child. The rest (90\%) were single and childless.

The documentary study of the students' scores showed that they got more 3.5 GPA in average. Their GPA was considered as very good academic achievement. The documents also showed that they also successful in the other area. One of the achievements was the second runner-up of Kakang Senduk Ponorogo 2015. There were also two students who got students' research grant from DIKTI on 2014/2015. All of the subjects also had got the scholarship for students with high academic potential in different years.

\section{The Descriptions of Students' Abilities}

There were ten abilities of students' ability in applying autonomous learning. Those abilities were described in form of graphic from the questioner's result and the students' interview transcript.

\section{Graphic 1}

Students Ability to Motivate Themselves when Applying Autonomous Learning

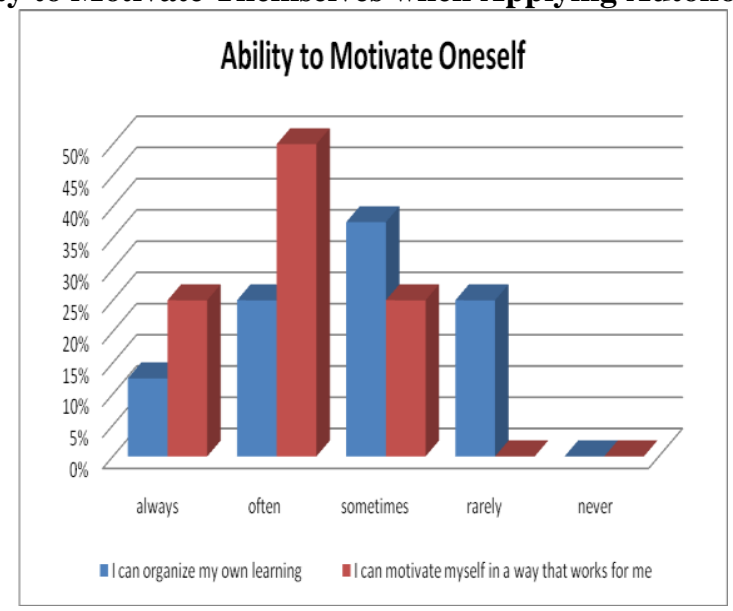

In Graphic I, there were two indicators which showed the students' perception on their ability to motivate themselves when applying autonomous learning. The first indicator was their perceptions on how often they could organize their way of learning. In Graphic 1, most of the students (38\%) considered themselves sometimes have the ability to organize their own way of learning. For the second indicator, $50 \%$ of the students considered they were often able to motivate themselves to do autonomous learning according to their own appropriate way of learning. 
The results of the interview which related to this ability were as follow:

"I motivate my own learning by realizing the goals that I should set for my learning"

"I said to myself that I still need to learn and extend my knowledge, because I realized that I was lacking of knowledge"

"I motivate myself through reflecting on what my friends/colleague had done, and assuring my own self that I can do the same, at least I should be able to do the same or even more"

"The more I learn, the more I realize that I know nothing. Thus, I should always learn and learn, either for academic or vocational purposes such as sewing, making embroidery, cooking, etc"

"I always want to be the best in all fields. It makes me always eager to learn so no one will be able to defeat me"

"by setting up my mind my initial learning goals"

"I motivate myself though watching some motivational clips"

"I always think that learning is the bridge to be able to compete in present and future. I am anxious that I would not be able to compete for life if I do not continue to learn"

Students' answers on interview about motivation showed that they were able to recognize which motivation will work best on them. Internal motivations such as their own wish to become the best and the self-pressure on the importance of learning were some of the students' way to motivating their own learning. Futhermore, they also used external motivation such as keeeping in mind the learning goal as the base of their motivation. Overall, the positive feelings such as contentment, pride, grateful, and the capability to do and finish particular things, tasks, or overcome any autonomous learning obstacles were considered able to motivate one self to stay learning.

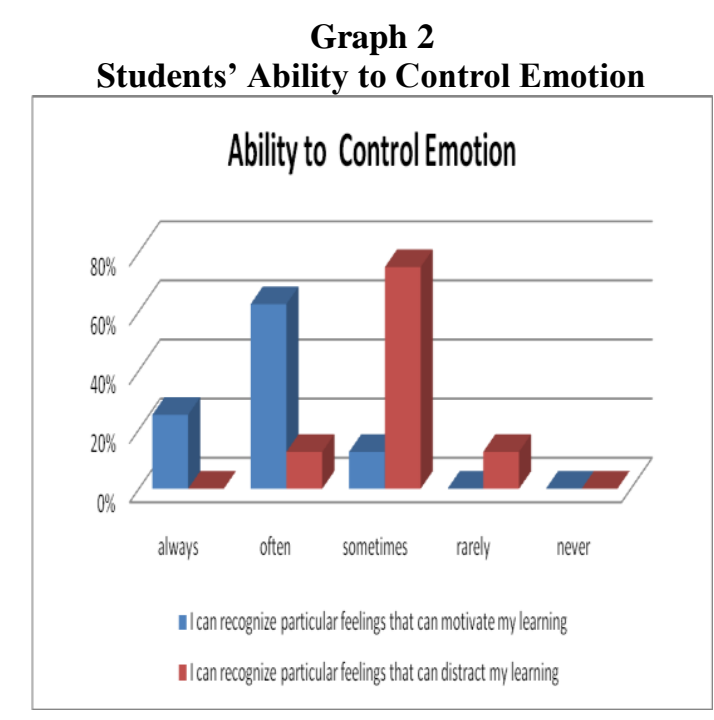

There were two indicators that can show the students' ability to control their emotion. The first indicator was how often they could recognize particular felings that can motivate their learning. The second indicator was how often the students could recognize particular feelings that can distract their learning. Based on Graph 2, there were $63 \%$ of the students were often able to recognize particular feeling that can motivate them in learning. Further interview revealed that the students used internal motivation as the most appropriate way to motivate themselves. The results were as follow:

"by having the belief that I can do something"

"I can motivate myself when I succeeded in finishing particular task or getting though particular learning obstacles with satisfying results”

"I can motivate myself through the pride I gain every time I can do my tasks well"

"I should keep in my mind that contentment is mostly misleading, if we feel contented with particular thing, it highly possible that we will stop our learning. It does happen in real life"

"I can motivate my self though the contented feeling I gained when I am able to make others learn particular learning materials. I do also feel grateful for given the opportunity to do such positive activity"

"I can motivate myself though the feeling of contentment for getting better result than I have ever standardized"

"I can motivate myself when I feel contented for being able to apply my knowledge" 
There were $75 \%$ students who admitted that they sometimes able to recognize particular feelings that can obstruct their learning.

The interview also revealed kinds of feelings that distract the students' learning motivation. The results were as follow:

"I get distracted when I am in a troublesome situation or whwn I feel bored"

"Boredom is the feeling that frequently distract my learning mood"

"I get distracted due to my fear and unconfidence of doing public speaking"

"When I learn something and I feel continous failures, then the feeling of giving up and boredom start to emerge"

"Boredom, I am the easily-get-bored-kind-of-person, even the smallest event can drive me to boredom and distract me from my learning"

"I can be distracted in my larning due to my lack of reading fondness"

"My learning motivation get distracted by my own fear of public speaking"

"My reading ability put me in trouble during the learrning because I feel sleepy easily when I read or learn. I also feel unconfidence when

I see other's well performance eventhough I realize that I can do the same."

Boredom was the feeling that the students mostly mentioned and considered as an obstruction to the learners. In addition, fear, lacking of confidence, and giving up were named among the feelings that can obstruct the students' learning. Their lack of reading fondness also became the trigger of learning laziness which eventually leads to students learning obstruction.

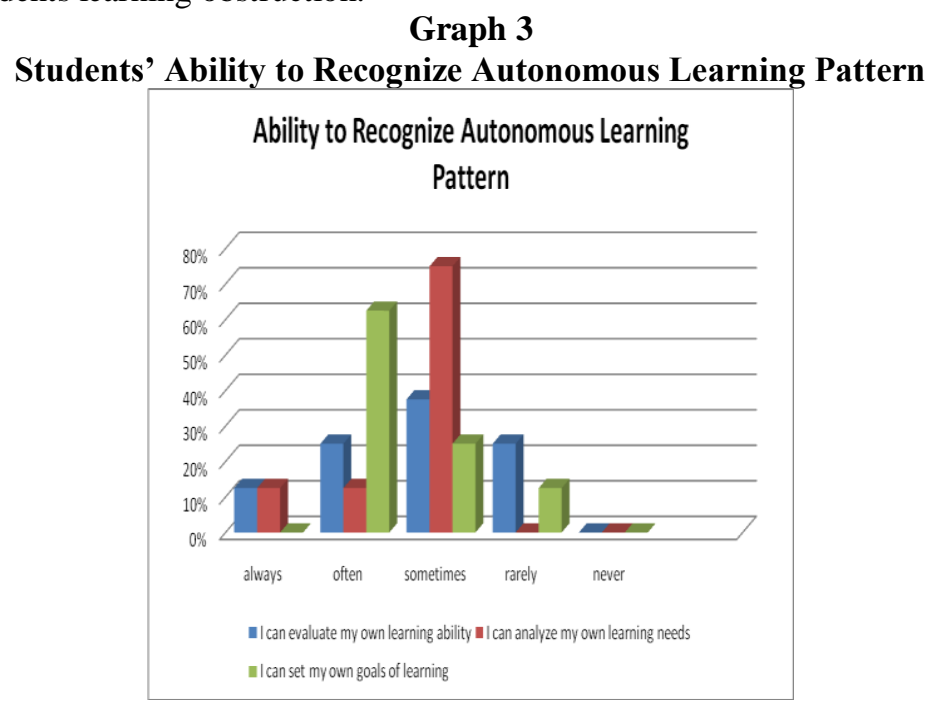

There were three indicators that showed the students' ability to recognize the autonomous learning pattern. The first indicator was how often they could evaluate their own learning ability. The second indicator was how often they could analyze their own learning needs. The third indicator was how often they could set their own goals of learning.

For the first indicators, there were $38 \%$ of the students who stated that they were sometimes able to evaluate their own learning ability. For the second indicator, there were $75 \%$ students stated that they were sometimes able to analyze their own learning needs. For the third indicator, $63 \%$ of the students felt that they were sometimes able to set their own goals of learning when they learn independently. In the interview, they said that their goals in learning were as follow:

"My goals were being able to comprehend and applied my knowledge"

"My specific goal in learning English is to enlarge my English knowledge especially in speaking skills"

"My goals is to get job which is related with my current field of study"

"I want to be able to speak English fluently and get a lot of friend worlwide to open any opportunities for working abroad"

"I want to be able to speak English fluently "

"I want to apply my knowledge of English to those who need it" 
On the interview about their goals of learning English, the students gave various answers. Their answers ranged from the general to the specific one. The students' answers were mostly based on the imprtance of English for their future working requirements.

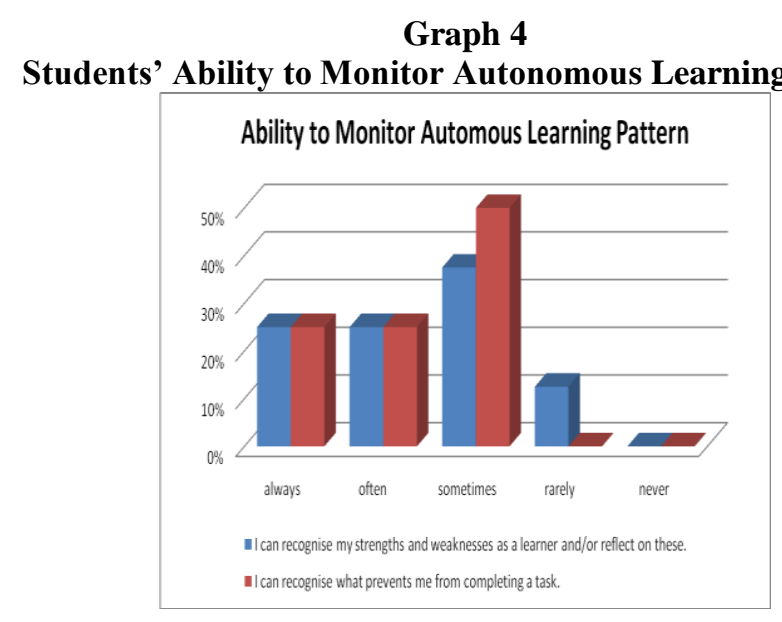

There were two indicators that show the students ability to monitor their outonomous learning pattern. The first indicator was how often they could recognize their streghs and weaknesess as a learner and/or reflect on these. The second was how often they could recognize what prevent them from completing task.

For the first indicator, there were $38 \%$ students that stated they were sometimes able to recognize their strengths and weaknesess as a learner and/or reflect on these. For the second indicator, there were $50 \%$ of the students stated that they were sometimes able to recognize what prevent them from completing task.

Based on the interview, there were some things that the students considered as things that can recognize what prevent them from completing task:

"The inability to manage time"

"Exhaustion and sleepyniess due to the morning work and the obligation to study on the evening, and sometimes we got too sleepy to study at night"

"boredom and bad mood"

"laziness factor and the fact that I like to put off what I can do today because other activities"

"boredom, hunger, laziness, mood"

"the teaching does not suit the materials given"

Boredom, laziness, and exhaustions were top three anwers for the feelings that the students considered as things that prevent them from completing task.

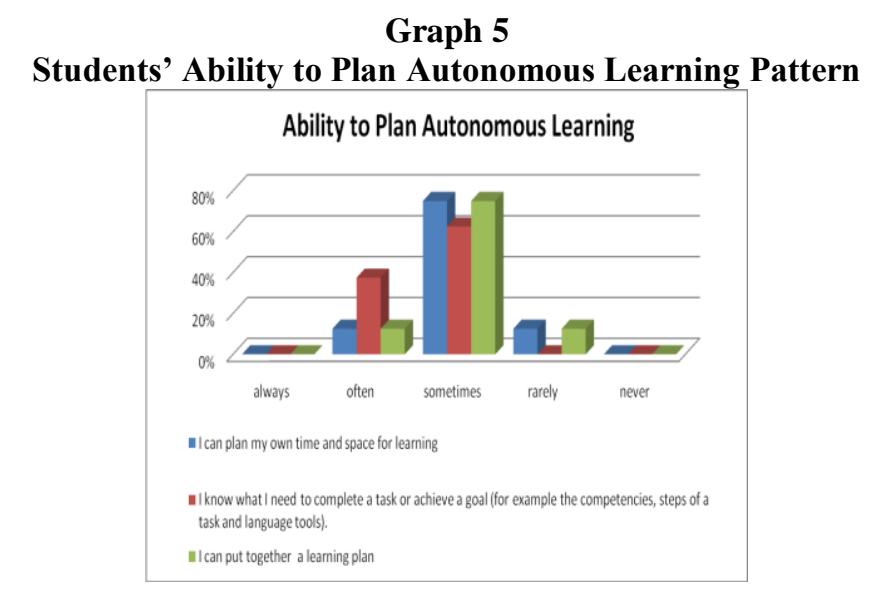

There were three indicators for this ability. The first indicator was how often they could plan time and place for learning. The second ability was how often they could know what they need to complete a task or achieve a goal (for example the competencies, steps of a task and language tools). The third indicator was how often they could put together a learning plan. $75 \%$ of the students thought that they were sometimes able to plan their own time and space for learning. $63 \%$ of the students thought that they were sometimes able to know what 
they need to complete a task or achieve a goal. $75 \%$ of the students thought that they were sometimes able to put together a learning plan.

Based on the interview, the students revealed the description of the appropriate time and space for them were the time and space which coulb be adjusted to their work or other extracuricular activities; and family responsibility.

"I set my learning time and space according to my current condition"

"I am rather be in neat and comfortable space in the morning tostudy"

"I rather be in rather quiet place and have good internet connection"

"The most effective time to learn for me as a mother, is when my son had fallen asleep"

"I learn when I had finished my workload"

The students' answers implicitly described the general description of the nontraditional students (having either professional or familial responsibility in addition to the learning activity which was done in the afternoon when the brain starts to decrease their focus and ability to think). Their inability to plan exact time and space for learning was related to the condition and daily situation they face everyday. Due to the workload and family responsibility they tended to learn in unspecified time and space. They tended to learn after they had done their professional and social-familial responsibilities. Yet, they prefered to have a quiet, peaceful, and comfortable place in the morning to learn.

When the students were asked about things that they needed to complete a task, their anwers were competency, references related to the material, motivation, clear learning steps, passion, and gratitude.

Based on interview, the students planned their learning independently by collecting various learning resources which were related to the materials. Then, they ordered it based on specific way to arrange their learning independently. Those were as follow:

"I arrange my learning by starting it from the easiest/ the simplest to the most complicated ones

"I start my learning by reading the textbooks and find other references if there are some difficulties in understanding the materials"

"I usually collect various learning recources in internet and then I reconstruct my knowledge with my own word"

The students' description about their learning needs included the availability of mentors, textbooks, and self-disipline. Only one of the students answered that she rather chose to learn alone at home without help from others.

\section{Graph 6}

Students' Ability to Choose Materials and Method of Autonomous Learning

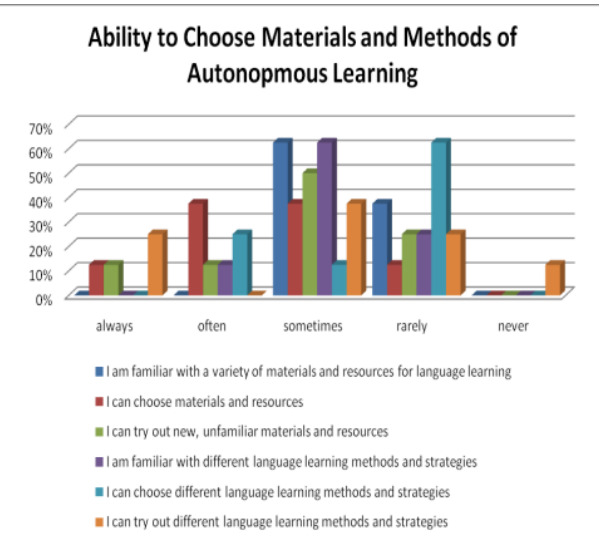

There were six indicators in this ability. The first indicator was how often the students could be familiar with a variety of materials and resources for language learning. The second indicator was how often the students were able to choose materials and resources. The third indicator was how often the students could try out new, unfamiliar materials and resources. The fourth indicator was how often the students could be familiar with different language learning methods and strategies. The fifth indicator was how often the students could choose different language learning methods and strategies. The sixth indicator was how often the students could try out different language learning methods and strategies.

There were $63 \%$ students that sometimes able to get familiar with a variety of materials and resources for language learning. There were $38 \%$ of the students who gave similar percentage to the option of sometimes and often for their ablity to choose materials and resources. There were $50 \%$ of the students who thought that they were sometimes able to try out new, unfamiliar materials and resources. There were $63 \%$ students that rarely able to get familiar with different language learning methods and strategies. There were $63 \%$ students that sometimes able to choose different language learning methods and strategies. There were $38 \%$ students that sometimes able to try out different language learning methods and strategies. 
Based on the interview, the students were still accostumed to the use of less variety of materials and resources for language learning. They also tended to use the traditional method and strategy for language learning. The interview also revealed that the students used various kinds of materials and learning resources by classifying it into its relevances with the learning materials. After the classification, they will try to use them to understand the concept and the material given. They also used the internet as their learning resource to help their learning. They revealed that the basis to choose the appropriate learning method and strategy were their mood and the relevance between the learning method and strategy to the learning materials. The learning method and strategy which they frequently used were discussion, reading aloud, cooperative learning, and individual learning. The kinds of learning method and strategy that they wanted to try was learning with native speaker to increase their speaking ability. To increase their ability to write they wanted to use modelling strategy by means of standardized essays or other writings. They wanted to use the relevant textbook such as Betty Azar's grammar textbook to learn grammar. They frequently use music, film, video, essay, and smartphone application to help their learning. Audio visual media were more preferable by most of the students $(80 \%)$ for their learning

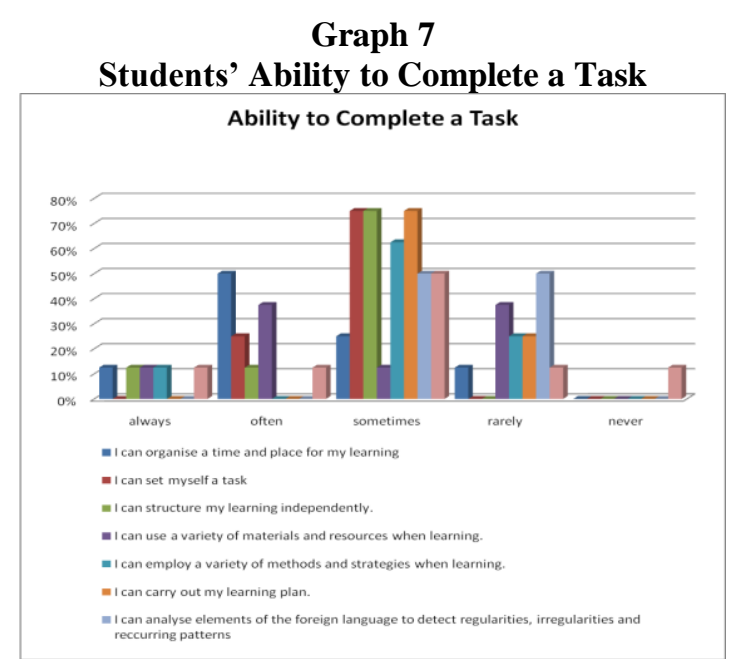

There were eight indicators that showed the students's ability to complete a task. The first indicator was how often the students could organise a time and place for their learning. There were $50 \%$ students that stated they were sometimes able to organise a time and place for their own learning. The second indicator was how often does the students set themselves a task. The biggest percentage (75\%) of the students stated that they were sometimes able to set themselves a task. The third indicator was how often the students could structure their learning independently. There were $75 \%$ of the students who stated that they were sometimes able to structure their learning independently. The fourth indicator was how often the students could use a variety of materials and resources when learning. There were 38\% students stated that they sometimes able to use a variety of materials and resources when learning.

The interview revealed that the students started their learning by doing as follow:

"I usually learn grammar before I learn writing"

"I usually have to understand the concept before doing the task"

"I have to know the meaning of particular words dan read it more than once to really understand it"

"I tend to learn better by example"

"I do learning by doing to increase my speaking skill"

"I start to learn if I have already understood the meaning of particular text related to the materials"

"I tend to start my learning by practising my skills"

The fifth indicator was how often the students could employ a variety of methods and strategies when learning. There were $63 \%$ students said that they were sometimes able to employ a variety of methods and strategies when learning.

In the interview, the students showed how they use various learning material and resources as follow:

"I only take the most relevant points of the learning process'

"I classify the resources according to the relevant learning materials"

"I tend to understand each of the learning materials based on the most relevant sources"

"I will find other sources in the internet, if I do not really understand the materials"

"I tend to make draft for my learning such as writing my own PPT and I will write the notes on it with various color"

"I tend to make conceptual mind map to correlate various learning materials to make them easier to be understood." 
"I tend to do the learning eventhough I have less understanding on it"

According to the interview, the following learning material and resources that they frequently used were as follow:

"for listening skills, I usually listen to music and film"

"for essay writing, I usually use reading resources and relevant model essays"

"for listening skills, I usually use kinds of expressions as the main resources"

"I prefer to learn English through reading or seeing the native speakers' video"

"I learn grammar through one of the application in my smartphone"

"I use audio visual media to support my listening and speaking skills"

"I usually read some short stories"

"I usually watch some video for example the video on how to write narrative text"

The sixth indicator was how often the students could carry out their learning plan. There were $75 \%$ of the students that stated they sometimes were able to do so. Based on the interview, the students do their learning plan as follow:

"I do my learning as it planned but sometimes the situation and mood affect the learning too"

"I do my learning as it planned and I arranged it from the simplest to the hardest"

"I do my learning based on the situation, but mostly not really different from the initial plan"

"I do my learning plan as I wish and in accordance to my ability, and I usually do it when my son had slept"

"I do my plan according to my wish but sometimes I do it differently based on the relevant learning materials"

The students learning plan sometimes was not able to be carried on due to their limitation of supportive time and condition.

The seventh indicator was how often the students could analyse elements of the foreign language to detect regularities, irregularities and reccurring patterns. $50 \%$ of the students said they were often able to analyse elements of the foreign language to detect regularities, irregularities and reccurring patterns. The other $50 \%$ said that they were sometimes able to analyse elements of the foreign language to detect regularities, irregularities and reccurring patterns.

The eighth indicator was how often the students could analyse texts, conversations and other communication in the foreign language and recognise specific (cultural) aspects of the communication. Most of the students $(50 \%)$ stated that they were sometimes able to analyse texts, conversations and other communication in the foreign language and recognise specific (cultural) aspects of the communication.

Based on the interview, the students revealed that they did not really understand how to analyse texts, conversations and other communication in the foreign language and recogni could e specific (cultural) aspects of the communication. Only some of them could analyse texts, conversations and other communication in the foreign language and recognise specific (cultural) aspects of the communication. The difference of accent was one of the communication aspects that the students can analyze.

The transcript was as follow:

"Sometimes I am able to recognise specific (cultural) aspects of the communication"

"I analyze the spoken language by differentiating the accents of the native speakers"

Graph 8

Students' Ability to Reflect the Autonomous Learning Pattern

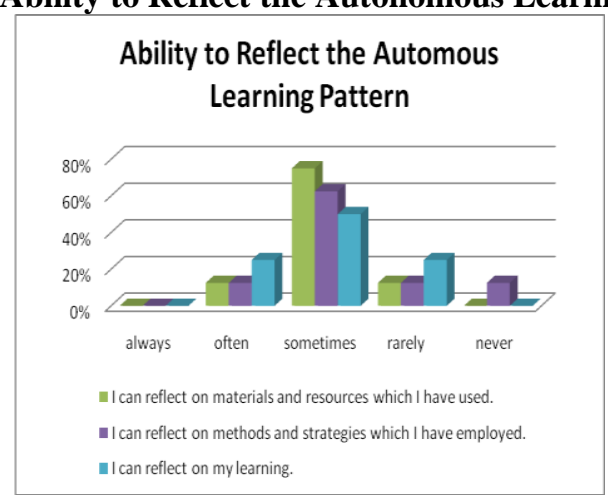


There were three indicators to show the students' ability to reflect on the autonomous learning pattern. The first indicator was how often the students could recognise their strengths and weaknesses as a learner and/or reflect on these. $75 \%$ of the students stated that they were someties able to recognise their strengths and weaknesses as a learner and/or reflect on these.

On the interview the students described their strengths and weaknesess as folow:

"I am not really able to manage time"

"My strengths are I can easily understand something and I do my task efficiently and effectively, my weaknesess were I tend to forget things easily and less expressive"

"My strength is that I can understand sometging easily, my weakness is my tendency to forget things easily"

"My weakness is my lacking of confidence"

"I can easily understand the lesson which uses simple language"

"My strength was my bravery in expressing opinion/ideas; my weakness is I like to put off the work"

"My weakness is I am sometimes afraid to express my opinion and feel embarassed, I have the strengths in speaking with fluent pronunciation"

"I do not really aware on my strenght; my weaknesess are lack of confidence and do not belief good result can be gained easily3"

The second indicator was how often the students could the reflect on methods and strategies which they have employed. $63 \%$ of the students stated that they sometimes reflect on methods and strategies which they have employed.

The third indicator was how often the students could reflect on their own learning. $50 \%$ of the students stated that they sometimes reflect on my learning.

Based on the interview with the students about the description on their strengths and weakneses, the students showed more awareness on their weaknessess than their strenghts in learning. Their weakness were the lack of time management, lack of confidence, and easily forget. Generally, the students' strenghts were: easy to understand the learning materials especially when it was delivered through simple language, eager to express their opinion, and able to do the task efficiently and effectively.

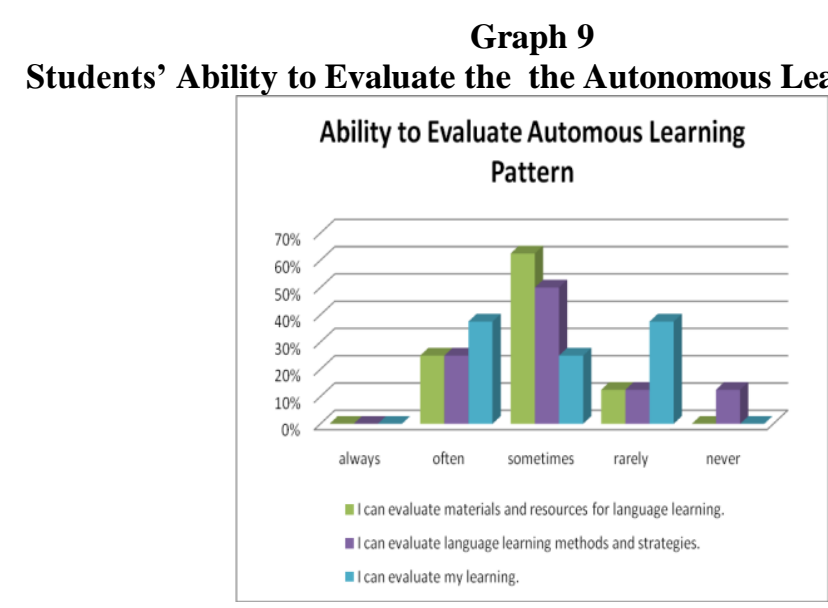

There were three indicators of the students' ability to evaluate the the autonomous learning pattern. The first indicator was how often the students could evaluate materials and resources for language learning. $63 \%$ of the students stated that they were sometimes able to evaluate materials and resources for language learning. The second indicator was how often the students could evaluate language learning methods and strategies. 50\% of the students stated that they were sometimes able to evaluate language learning methods and strategies. The third indicator was how often the students could to evaluate their learning. There were $38 \%$ students stated that they were often able to evaluate their learning. Bt, there were also $38 \%$ students stated that they were rarely able to evaluate their learning. There were two opposing opinions toward how often does the students able to evaluate their learning

\section{Graph 10}

Students' Ability to Cooperate in the Autonomous Learning 


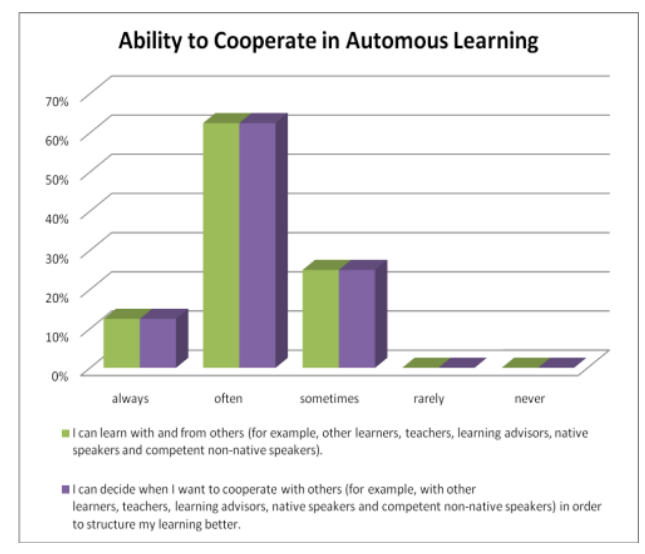

There were two indicators that showed students' ability to cooperate in the autonomous learning. The first indicator was how often the students could learn with and from others (for example, other learners, teachers, learning advisors, native speakers and competent non-native speakers). $63 \%$ of the students stated that they were often able to learn with and from others (for example, other learners, teachers, learning advisors, native speakers and competent non-native speakers).

The students stated from the interview that there were several circmstances that enable them to learn with and from others. The circumstances were as follow:

"I can learn with and from others but I had to get adjusted to them"

"I can learn with anyone, but learning with native speakers will make it easier for me to learn the language compared to learning with local speaker"

"I prefer to learn with native speakers but I still can manage to accept the simple learning process"

On the interview, the students also revealed the circmstances that enable them to learn from and with others. The circumstances were as follow:

"I can learn from and with others if I am not pleased or feel any unequality between my effort and my result"

"I would like to learn from and with others as soon as possible, because I realized that my learnong organization was still unstructured"

"I would like to learn from and with others anytime, especially on the materials that I want to learn and comprehend more"

"Not until I have been in the most boring and difficult point that I start to ask someone a questions"

"I would prioritize myself to learn from and with others who I considered to be more competent"

"I would like to learn from and with others if I have not been able to handle my learning problems any more"

"I would like to learn from and with others antime, especially when I have not understand the laerning materials"

The second indicator was how often the students could decide when they want to cooperate with others (for example, with other learners, teachers, learning advisors, native speakers and competent non-native speakers) in order to structure their learning better. $63 \%$ of the students stated that they were often able to decide when they want to cooperate with others (for example, with other learners, teachers, learning advisors, native speakers and competent non-native speakers) in order to structure their learning better.

People who they considered to be able to help them during the autonomous learning were as follow:

"fellow classmates then the lecturers"

"tecturer, friends"

"the more competent classmate (close friend)"

"my best friend"

"my husband and my friends"

"the lectures who want to and is willing to help theeir students to overcome their learning 's problem"

\section{Discussion}

The research was explicitly studied about two out of three autonomous learning stategies by O'Malley \& Chamot's; metacognitive stategy and social mediation strategy. The metacognitive strategy which were studied in this reseach covered the planning for learning, self supervision, self evaluation, and constructing personal learning file. Social mediation strategy that studied in the research was mostly concerned on the students' attitude on the application of learning cooperation (Wang, 2010). This research did not explicitly study about cognitive stategy, yet did it not study the students' specific stategy in particular English skills. 
The students' awareness on their ability to motivate themselves can be a resourceful capital for their further learning autonomy. This awareness can trigger the development of other ability especially the ability to recognize their strengths and weaknesses in learning. Once they realize their strenghts and weaknesses in learning, the students will get easier to find out about the method, strategy, resources, and media which they can employ best for their success in learning. Most of the nontraditional students have positive atttitude toward the application of cooperation for autonomous learning. But, there was a tendency that their personal attitude toward particular cooperation partner affects their personal preference.

This reseach studied ten students' abilities in autonomous learning. There were two abilities that the successful nontraditional students often employed for autonomous learning. The abilities were the ability to motivate their own selves and the ability to cooperate in autonomous learning. The succesful non traditional students did not really apply and aware of their ability to control emotion, plan the learning, choose the material and method for autonomous learning, recognize the autonomous learning pattern, monitor the autonomous learning patteern, reflect the autonomous learnig pattern, complete the task, and evaluate the autonomous learning pattern. The successful non traditional students were sometimes able to aware of the application of those abilities. It indicates that the successful nontraditional students were not fully aware on and apply the strategy during the autonomous learning.

The result of the study showed the students were sometimes able to control their emotion. Their lack of ability in controlling emotion may be due to the declining mental and phisical condition since the lectures were held in the afternoon .It may also be the effect of exhaustion due to the workloads in the office, family, and other extracuricular activities.

Most of the students stated that they were sometimes able to plan their learning. The nontraditional students were not accustomed to plan their learning in detailed and correct steps. Most of the students also stated that they were sometimes able to choose the material and method for autonomous learning. It seemed that they were not too eager in choosing the material and method for their own learning. They tend to accept any material and method given by the lecturers. They also stated that they were sometimes able to recognize the autonomous learning pattern, monitor the autonomous learning patteern, reflect the autonomous learnig pattern, complete the task, and evaluate the autonomous learning pattern. Their answers may be an indications of either their unawareness or ingnorance toward their own ability to apply the autonomous learning stategy.

Since the nontraditional students had got other responsibilies beside studying, flexibility; in term of time, space, method, strategy, resources, media, and learning material, became the most important key for their learning success. They were "forced" by their nontraditional situation to be able to do their learning flexibly: boundless and limitless. This was in line with Kupetz \& Ziegenmeyer's research that (2006) which emphasized the flexibility as crucial points in ssupporting the construction of autonomous learning pattern. It then provides a solid base to support the success of individual's success in learning English in the classroom. Flexibility became the nontraditional students' route to their academic success while juggling at other responsibilities in life.

The students showed the flexibility of learning time because they had to make sure that they had already finished their responsibilites before starting their study. This showed that the students had high commitment to complete a task. Unfortunately, it seemed that they put their learning responsibilities after their other responsibilities. Yet, for the successful non tradional students morning became their most prefered time for learning The successful on traditional students stated that they can learn in any place. To balance their professional or familial responsibilities with their academic responsibilities, they must make themselves able to learn anywhere in limited time. Yet, a cozy, quiet, and comfortable place to study were more preferable.

Eventhough the result of the quissionaire showed that the students were sometimes able to choose their own method, strategy, resources, media, and learning material for their learning success, all of the students were eager to do better with those crucials acpects in learning. Those abilities indicates the application of autonomous learnig strategy of the successful non traditional students. The application of autonomous learning stategy showed some merits as there were stated by Long, Pao-Nan, and Wei-Fan (in Francis and Flanigan, 2012: 2), autonomy learning shows a positive correlation with students' achievement. Moreover, the autonomous learning stategy encourage the non traditional student to have more confident and responsibility, enlarge their learning opportunity beyond the other responsibilities, and focus the students' attention.

Since autonomous learning mostly focuses on individual learner, their individual preference became crucial factor. The successful non traditional students need to do extra hard-working to achieve goals as what have been planned in the beginning. The interaction between the less preferable lectures and friend is likely to happen. It 
may also be a challenge for both of the students and the lecturers on how to compromise the different learning strategy in the classroom setting.

\section{E. CONCLUSION AND SUGGESTIONS}

Autonomy learning is a learning process which aims to develop student's capability and responsibility in learning process. Various definitions and theories of autonomy learning reveal that it is important to develop student's self-competence. There is a positive correlation between autonomy learning and the significant improvement of student's competence.

The result of this study showed the general description of the successful non traditional students of English Education program in STKIP PGRI Ponorogo. It did not cover the specific description on how the sucessful nontraditional students employesd the autonomous learning strategy for learning particular English skills. There fore this research mostly covered two kinds of autonomous learning stategy which were metacognitive stategy and social mediation stategy.

Futher researches on cognitive stategy for each English skilss are highly recommende to add detailed description on students' autonomous learning strategy. Further reseach may also cover the comparation between the successful traditional and non traditional students' strategy of autonomous learning. as follow:

Some suggetions were made by the researcher on the basis of the research result. The suggestions were

For the students, they should (1) be more aware on their streghts and weakneses as a learner, (2) be able to plan for their own learning, (3) be exposed further and more thoroughly on the abilities needed for effective autonomous learning. The students can have a consultation session on how to reorganize their autonomous learning with the leacturers or with their academic cunsultant. The consultation will help them to gain more overall detection and solution for their leaning in general. Further and more thorough exposes on the abilities needed for the aplication of autonomous learning must be beneficial to both nontraditional dan traditional students in general. It will also help them to increase their determination and commitment for planning their own learning needs.

To increase their flexibility in cooperation, the students must be advised to put aside their personal preferences. They must keep in their mind that they must be able to cooperate with anyone as long as they are competent with the field of the study. that belief will help them get along easier with other people whose competency will help them to gain their success in learning.

There are some suggestions for the lecturers or the academic advisors. The sugesstions were the lecturers or the academic advisors should be able to motivate and help the students to recognize their strenghts and weaknesess. The motivation can be in the form of moral support for the students to learn better. The lecturers or the academic advisors can have either private or open discussion with the students about how to maximize their strenghts in learning and overcome their weaknesses. During the discussion, the lecturer or academic advisors can bring about their observation on the students during the leaarning process as additional information to the identication on the students' learning. Employing various teaching and learning method, strategy, media, dan resources during teaching and learning process are more preferable.

The institution can also take part to increase the students' autonomy in learning. They can set particular time before or after the semester to do a kind of scheduled councelling session for the students especially for the non traditional students. If it is possible the councelling session shoulf be done with the professional academic councelor, so that the students can get thorough insight about their learning. The institution can also do futher research in autonomous learning and publish the result so that the students and the lecturers can create more optimal teaching and learning process.

\section{F. REFERENCES}

Buvoltz, K. A., Powell, F. J., Solan, A. M., \& Longbotham, G. J. (2008). Exploring Emotional Intelligence, Learner Autonomy, and Retention in an Accelerated Undergraduate Degree Completion Program. New Horizons in Adult Education \& Human Resource Development, 22(3), 26-43. Retrieved from http://search.proquest.com/docview/194674935?accountid=25704

Francis, A. \&Flanigan, A. (2012). Self-Directed Learning and Higher Education Practices: Implications for Student Performance and Engagement. International Journal of the Scholarship of Teaching and Learning, 7(3): $1-18$

Kupetz, R., \& Ziegenmeyer, B. (2006). Flexible Learning Activities Fostering Autonomy in Teaching Training. ReCALL : The Journal of EUROCALL, 18(1), 63-82. Retrieved from http://search.proquest.com/docview/223239119?accountid=25704 
McDonough, S. K. (2001). Promoting Self-Regulation in Foreign Language Learners. The Clearing House, 74(6), 323-326. Retrieved from http://search.proquest.com/docview/196876708?accountid=25704

Tassinari, M. G. (2012). Evaluating Learner Autonomy: A Dynamic Model with Descriptors. Studies in SelfAccess Learning Journal, 3(1), 24-40.

Sariçoban, A. (2012). Metacognitive Strategies and Learner Autonomy in EFL Reading. Modern Journal of Language Teaching Methods, 2(2), 45-68. Retrieved from http://search.proquest.com/docview/1145544978?accountid=25704

Wang, J. (2010). How to Develop College Students' Autonomous English Learning Skills-Take Reading Course in Joint-Program in HCFT as an Example. English Language Teaching, 3(3), 221-228. Retrieved from http://search.proquest.com/docview/839071133? accountid=25704

Zoghi, M., \& Dehghan, H. N. (2012). Reflections on What of Learner Autonomy. International Journal of English Linguistics, 2(3), 22-26. Retrieved from

http://search.proquest.com/docview/1045448342?accountid=25704 